TITLE:

\title{
A chiral phosphoric acid catalyst for asymmetric construction of 1,3- dioxanes.
}

\section{AUTHOR(S):}

Matsumoto, Akira; Asano, Keisuke; Matsubara, Seijiro

\section{CITATION:}

Matsumoto, Akira ... [et al]. A chiral phosphoric acid catalyst for asymmetric construction of 1,3-dioxanes.. Chemical communications 2015, 51(58): 11693-11696

ISSUE DATE:

2015-06-12

URL:

http://hdl.handle.net/2433/201598

\section{RIGHT:}

This journal is (c) The Royal Society of Chemistry 2015.; The full-text file will be made open to the public on 09 June 2016 in accordance with publisher's 'Terms and Conditions for Self-Archiving'.; この論文は出版社版でありません。引用の際 には出版社版をご確認ご利用ください。; This is not the published version. Please cite only the published version. 


\section{Journal Name}

\section{COMMUNICATION}

\section{A chiral phosphoric acid catalyst for asymmetric construction of 1,3-dioxanes}

Received 00th January 20xx, Accepted 00th January 20xx

DOI: $10.1039 / \times 0 \times x 00000 x$

\author{
Akira Matsumoto, Keisuke Asano, * and Seijiro Matsubara*
}

www.rsc.org/

A novel method of enantioselective 1,3-dioxane construction via a hemiacetalization/intramolecular oxy-Michael addition cascade by a chiral phosphoric acid catalyst was developed. The product was successfully transformed into an optically active 1,3-polyol motif, indicating that the proposed reaction can provide useful chiral building blocks for the de novo synthesis of polyketides.

The oxy-Michael addition is one of most important methods for the introduction of oxygen to the $\beta$-position of carbonyl compounds. ${ }^{1}$ In particular, stereoselective construction of 1,3-dioxanes via a hemiacetalization/intramolecular oxy-Michael addition cascade is a well-designed approach to synthesize stereodefined 1,3-diols found in polyketides, which are promising candidates for therapeutics (Scheme 1 and Figure 1). ${ }^{2,3}$ Indeed, such transformations have been utilized in the synthesis of a number of pharmacologically important molecules. ${ }^{4} \quad$ However, although several diastereoselective methods from chiral substrates under basic or acidic conditions have been reported, ${ }^{5}$ enantioselective methods have remained largely unexamined thus far due to the lack of a useful strategy for asymmetric induction in the intramolecular oxyMichael addition reaction.

$$
\text { (N) }
$$
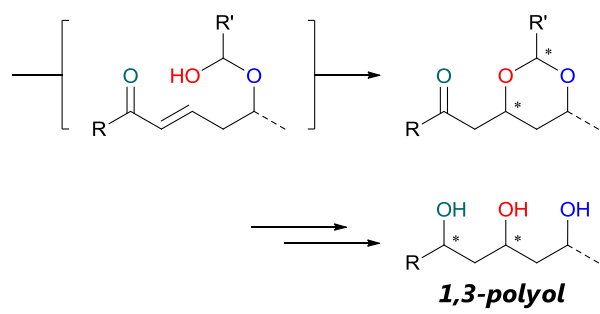

Scheme 1. 1,3-Dioxane construction via hemiacetalization/intramolecular oxy-Michael addition cascade.

\footnotetext{
Department of Material Chemistry, Graduate School of Engineering, Kyoto University, Kyotodaigaku-Katsura, Nishikyo, Kyoto 615-8510, Japan. E-mail: asano.keisuke.5w@kyoto-u.ac.jp, matsubara.seijiro.2e@kyoto-u.ac.jp; Fax: +81 75383 2438; Tel: +81753837571 +81753837130

Electronic Supplementary Information (ESI) available: Experimental procedures, analytical and spectroscopic data for synthetic compounds, copies of NMR. See DOI: $10.1039 / x 0 x x 00000 x$
}

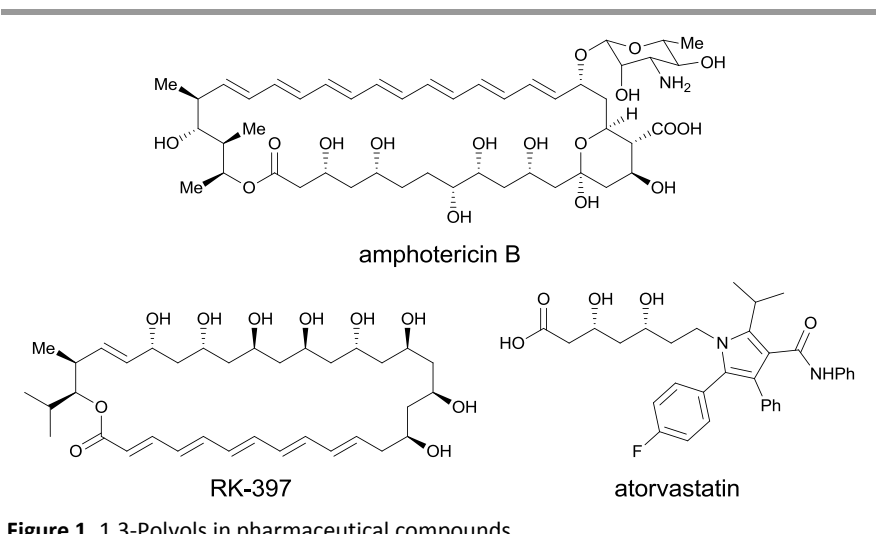

Figure 1. 1,3-Polyols in pharmaceutical compounds.

Recently, we have developed an efficient methodology for enantioselective intramolecular oxy-Michael addition reactions by utilizing multipoint recognition through hydrogen bonding with bifunctional organocatalysts. ${ }^{6-8} \quad$ Intramolecular oxy-Michael additions from hemiacetal intermediates to afford 5-membered cyclic acetals, namely 1,3-dioxolanes, were conducted by using bifunctional aminothiourea catalysts. Such transformations, followed by deacetalization, proved efficient protocols for formal hydration to afford optically active polyols. ${ }^{6 b, c, f}$ However, as the aminothiourea catalysts do not have a sufficient activity to effect the construction of 6-membered 1,3-dioxanes, we chose to focus on chiral phosphoric acids, because they have moderately higher acidity than thioureas and the following merits. ${ }^{9}$ Firstly, the phosphoric acid catalysts possess both acidic and basic sites, allowing for multipoint recognition of a substrate through hydrogen bonding in the oxycyclization. In additioin, such dual functionality provides double activation of a substrate for cyclization, thus leading to sufficient catalytic activity even without particularly high acidity, which is unsuitable in this transformation since the hemiacetal intermediates or the acetal products will be decomposed through the formation of oxocarbenium ions. Finally, an appropriate choice of substituents at the 3- and 3'-positions of the catalysts enables their acidity and steric character to be finely tuned. Herein, we demonstrate novel asymmetric 1,3-dioxane 
formation via a hemiacetalization/intramolecular oxy-Michael addition cascade using a chiral phosphoric acid catalyst. ${ }^{10,11}$

Table 1. Optimization of conditions ${ }^{a}$

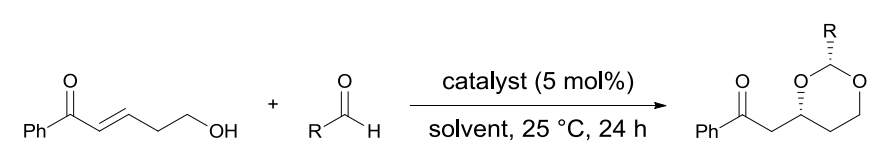

$1 \mathbf{a}$

2

3

\begin{tabular}{|c|c|c|c|c|c|}
\hline Entry & Catalyst & $\mathrm{R}(2)$ & Solvent & $\begin{array}{l}\text { Yield } \\
(\%)^{b, c}\end{array}$ & $\begin{array}{l}e e \\
(\%)\end{array}$ \\
\hline 1 & $4 a$ & Cy (2a) & benzene & 56 & 80 \\
\hline 2 & $4 b$ & Cy (2a) & benzene & 59 & 17 \\
\hline 3 & $4 c$ & Cy (2a) & benzene & 21 & -43 \\
\hline 4 & $4 d$ & Cy (2a) & benzene & 80 & 36 \\
\hline 5 & $4 e$ & Cy (2a) & benzene & 52 & 5 \\
\hline 6 & $4 a$ & $i-\operatorname{Pr}(\mathbf{2 b})$ & benzene & 57 & 79 \\
\hline 7 & $4 a$ & $i-\mathrm{Bu}(2 \mathrm{c})$ & benzene & 64 & 71 \\
\hline 8 & $4 a$ & $t-\mathrm{Bu}(2 \mathrm{~d})$ & benzene & 33 & 11 \\
\hline 9 & $4 a$ & Et (2e) & benzene & 60 & 78 \\
\hline 10 & $4 a$ & $n-\mathrm{C}_{5} \mathrm{H}_{11}$ (2f) & benzene & 74 & 86 \\
\hline 11 & $4 a$ & $n-\mathrm{C}_{9} \mathrm{H}_{19}(2 \mathrm{~g})$ & benzene & 72 & 82 \\
\hline 12 & $4 a$ & $\mathrm{PhCH}_{2} \mathrm{CH}_{2}$ (2h) & benzene & 76 & 85 \\
\hline 13 & $4 a$ & $\mathrm{Ph}(2 \mathrm{i})$ & benzene & $<1$ & - \\
\hline 14 & $4 a$ & $n-\mathrm{C}_{5} \mathrm{H}_{11}$ (2f) & toluene & 83 & 87 \\
\hline 15 & $4 a$ & $n-\mathrm{C}_{5} \mathrm{H}_{11}$ (2f) & hexane & 80 & 83 \\
\hline 16 & $4 a$ & $n-\mathrm{C}_{5} \mathrm{H}_{11}$ (2f) & c-hexane & 92 & 85 \\
\hline 17 & $4 a$ & $n-\mathrm{C}_{5} \mathrm{H}_{11}$ (2f) & $\mathrm{CH}_{2} \mathrm{Cl}_{2}$ & 76 & 68 \\
\hline 18 & $4 a$ & $n-\mathrm{C}_{5} \mathrm{H}_{11}$ (2f) & $\mathrm{Et}_{2} \mathrm{O}$ & 40 & 82 \\
\hline 19 & $4 a$ & $n-\mathrm{C}_{5} \mathrm{H}_{11}$ (2f) & $\mathrm{CPME}^{e}$ & 18 & 86 \\
\hline 20 & $4 a$ & $n-\mathrm{C}_{5} \mathrm{H}_{11}$ (2f) & EtOAc & 29 & 81 \\
\hline 21 & $4 a$ & $n-\mathrm{C}_{5} \mathrm{H}_{11}$ (2f) & $\mathrm{CH}_{3} \mathrm{CN}$ & $<5$ & 58 \\
\hline $22^{d}$ & $4 a$ & $n-\mathrm{C}_{5} \mathrm{H}_{11}$ (2f) & toluene & 54 & 93 \\
\hline $23^{d}$ & $4 a$ & $n-\mathrm{C}_{5} \mathrm{H}_{11}$ (2f) & $c$-hexane & 94 & 91 \\
\hline
\end{tabular}

${ }^{a}$ Reactions were run using $1 \mathrm{a}(0.1 \mathrm{mmol}), \mathbf{2}(0.12 \mathrm{mmol})$, and the catalyst $(0.005$ $\mathrm{mmol})$ in the solvent $(0.2 \mathrm{~mL})$. ${ }^{b}$ The diastereomeric ratio was $\geq 20: 1$ in all cases. ${ }^{c}$ Isolated yields. ${ }^{d}$ Reactions were run using $1 \mathrm{a}(0.1 \mathrm{mmol}), \mathbf{2}(0.2 \mathrm{mmol})$, and the catalyst $(0.005 \mathrm{mmol})$ in the solvent $(2 \mathrm{~mL})$ at $35^{\circ} \mathrm{C} .{ }^{e} \mathrm{CPME}=$ cyclopentyl methyl ether.

We began by investigating the reaction between $(E)$-5-hydroxy-1phenylpent-2-en-1-one (1a) and cyclohexanecarbaldehyde (2a) (Table 1) in the presence of $5 \mathrm{~mol} \%$ of chiral phosphoric acid catalysts 4 (Figure 2 ) in benzene at $25^{\circ} \mathrm{C}$. As expected, the 1,3dioxane product $\mathbf{3}$ was obtained enantioselectively as a single diastereomer (Table 1, entries 1-5), with (S)-TRIP (4a) proving the most promising among the various catalysts investigated (Table 1, entry 1). Using $\mathbf{4 a}$ as a catalyst, reactions with other aldehydes 2 were also investigated (Table 1, entries 6-13). While the use of pivalaldehyde (2d) resulted in poor enantioselectivity, unbranched aliphatic aldehydes were shown to be efficient, with $\mathbf{2 f}$ exhibiting the highest enantioselectivity (Table 1 , entry 10). The use of benzaldehyde (2i) was also investigated, but failed to afford the desired reaction product (Table 1 , entry 13 ). ${ }^{12}$ Subsequently, a range of reaction solvents were investigated (Table 1 , entries 1421), and it was found that less polar solvents gave improved yields and higher enantioselectivities (Table 1, entries 14-16). The enantioselectivity of the reaction was further improved by carrying out the reaction at lower concentrations in toluene at $35^{\circ} \mathrm{C}$ (Table 1 , entry 22). ${ }^{13}$ In addition, the use of cyclohexane as a solvent also resulted in an enhanced yield, and only a slight loss of enantioselectivity was observed (Table 1, entry 23).
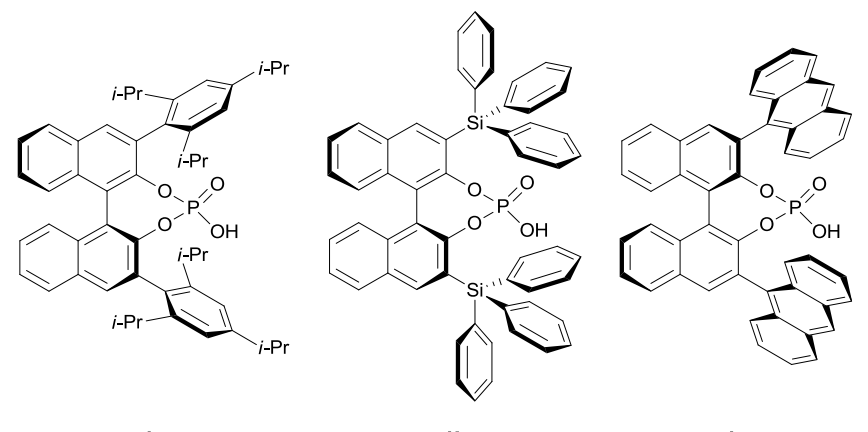

$4 a$

4b

4c
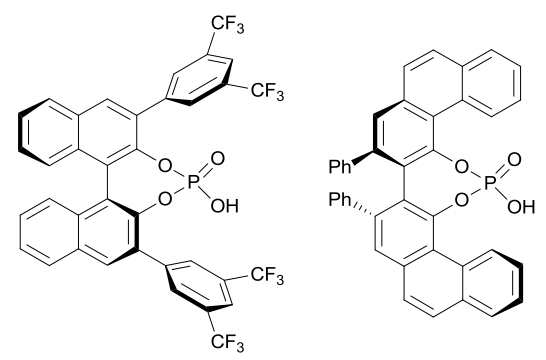

4d

$4 e$

Figure 2. Chiral phosphoric acid catalysts.

With the optimal conditions for the transformation established, we explored the substrate scope for the reaction (Table 2). It was found that both electron-rich and electron-deficient enones gave high enantioselectivities (3bf and 3cf). Substrates bearing 4methylphenyl, 2-naphthyl, and 4-bromophenyl groups were also suitable, and afforded the corresponding 1,3-dioxanes in high yields and enantioselectivities (3df, 3ef, and 3ff). In addition, although the use of an aliphatic enone resulted in moderate enantioselectivity under the current conditions (3gf), better enantioselectivity was attained in the reaction of an alkenyl ketone (3hf), allowing further modifications such as a regioselective hydration to approach higher polyols. Furthermore, although no desired product could be obtained in the reaction from an $\alpha, \beta$ unsaturated ester substrate, product $\mathbf{3 b f}$ could be transformed into the corresponding ester $\mathbf{5}$ by means of a Baeyer-Villiger oxidation using $m$-CPBA and TFA, without loss of optical purity (Scheme 2). This modification allows for further extension of this compound for the synthesis of longer polyketide structures through iterative manipulations of an established route, ${ }^{4 \mathrm{j}, \mathrm{k}, \mathrm{s}}$ consisting of the reduction to formyl group followed by allylation, olefin metathesis with acrylates, and another diastereoselective acetalization. ${ }^{5 a, b}$ Our product can therefore be regarded as a useful chiral building block for polyketide synthesis. The absolute configuration of 3ef was determined by X-ray crystallography (see the SI for details), and the configurations of all other products were assigned analogously. 
Table 2. Substrate scope

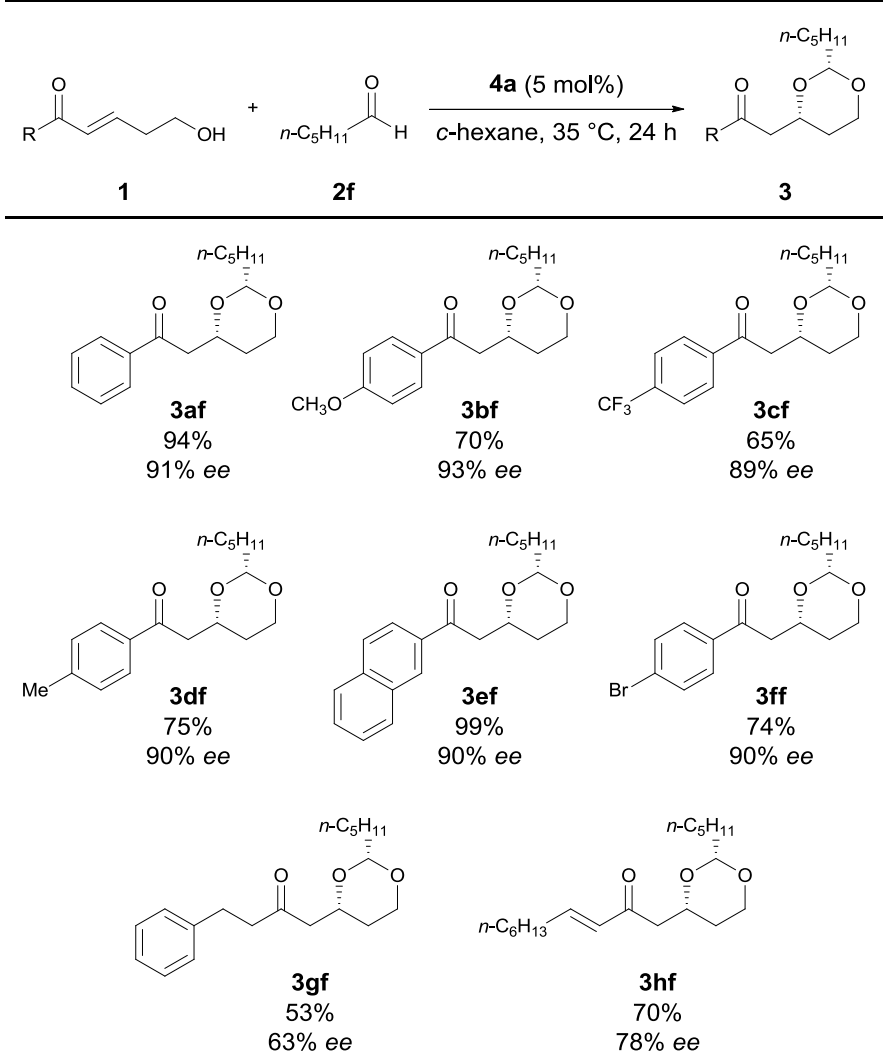

${ }^{a}$ Reactions were run using $\mathbf{1}(0.1 \mathrm{mmol}), \mathbf{2} \mathrm{f}(0.2 \mathrm{mmol})$, and the catalyst $\mathbf{4 a}(0.005$ $\mathrm{mmol})$ in cyclohexane $(2 \mathrm{~mL})$. Yields represent material isolated after silica gel column chromatography. The diastereomeric ratio was $\geq 20: 1$ in all cases.

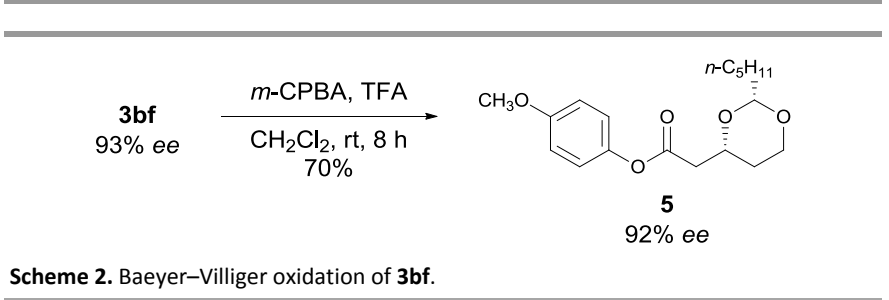

The use of our product in the asymmetric synthesis of a chiral 1,3,5-triol was then demonstrated. Reduction of 3af with lithium borohydride in the presence of europium chloride afforded the corresponding alcohols in a 12:1 diastereomeric ratio, in which synisomer 6 was the major product. ${ }^{14}$ Subsequent de-acetalization of the diastereomer mixture, followed by isolation of the major diastereomer using flash silica gel column chromatography, gave chiral 1,3,5-triol 7 with high optical purity (Scheme 3).

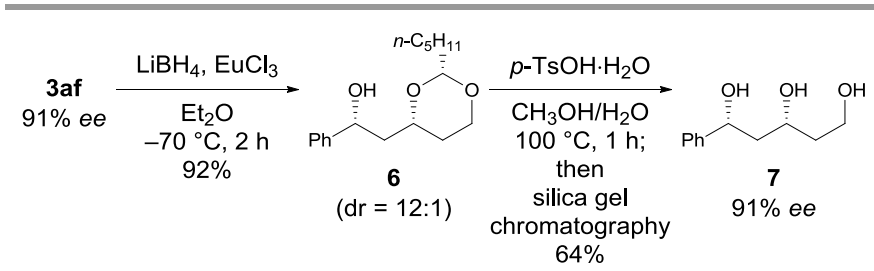

Scheme 3. Synthesis of chiral 1,3,5-triol 7.
In summary, we have presented a novel enantioselective hemiacetalization/intramolecular oxy-Michael addition cascade for the construction of 1,3-dioxanes, mediated by a chiral phosphoric acid catalyst. In addition, the utility of the products for the construction of stereodefined 1,3-polyol motifs was also demonstrated. These results indicate that the proposed methodology utilizing the dual functional organocatalyst opens a new avenue for the de novo synthesis of optically active polyketides. Investigation into the further sophistication of this synthetic method and its application to the asymmetric synthesis of attractive 1,3-polyol substructures from bioactive agents are currently underway, and the results will be reported in due course.

We thank Dr. Hiroyasu Sato (RIGAKU) and Professor Takuya Kurahashi (Kyoto University) for X-ray crystallographic analysis. This work was supported financially by the Japanese Ministry of Education, Culture, Sports, Science and Technology. K.A. also acknowledges the Asahi Glass Foundation, Toyota Physical and Chemical Research Institute, and Tokyo Institute of Technology Foundation.

\section{Notes and references}

1 For reviews on oxy-Michael addition reactions, see: (a) C. F. Nising and S. Bräse, Chem. Soc. Rev., 2008, 37, 1218; (b) E. Hartmann, D. J. Vyas and M. Oestreich, Chem. Commun., 2011, 47, 7917; (c) C. F. Nising and S. Bräse, Chem. Soc. Rev., 2012, 41, 988.

2 (a) J. Rohr, Angew. Chem., Int. Ed., 2000, 39, 2847; (b) D. J. Newman and G. M. Cragg, J. Nat. Prod., 2007, 70, 461; (c) G. M. Cragg, P. G. Grothaus and D. J. Newman, Chem. Rev., 2009, 109, 3012.

3 For reviews on stereoselective syntheses of 1,3-polyols, see: (a) T. Oishi and T. Nakata, Synthesis, 1990, 635; (b) C. Schneider, Angew. Chem., Int. Ed., 1998, 37, 1375; (c) K.-S. Yeung and I. Paterson, Chem. Rev., 2005, 105, 4237; (d) A. M. P. Koskinen and K. Karisalmi, Chem. Soc. Rev., 2005, 34, 677; (e) E. J. Kang and E. Lee, Chem. Rev., 2005, 105, 4348; (f) S. E. Bode, M. Wolberg and M. Müller, Synthesis, 2006, 557; (g) B. Schetter and R. Mahrwald, Angew. Chem., Int. Ed., 2006, 45, 7506; (h) M. B. Boxer, B. J. Albert and H. Yamamoto, Aldrichimica Acta, 2009, 42, 3; (i) J. Li and D. Menche, Synthesis, 2009, 2293; (j) A.-M. R. Dechert-Schmitt, D. C. Schmitt, X. Gao, T. Itoh and M. J. Krische, Nat. Prod. Rep., 2014, 31, 504; (k) D. Herkommer, B. Schmalzbauer and D. Menche, Nat. Prod. Rep., 2014, 31, 456.

4 For selected examples, see: (a) D. T. Hung, J. B. Nerenberg and S. L. Schreiber, J. Am. Chem. Soc., 1996, 118, 11054; (b) D. A. Evans, P. J. Coleman and L. C. Dias, Angew. Chem., Int. Ed. Engl., 1997, 36, 2737; (c) D. A. Evans and B. T. Connell, J. Am. Chem. Soc., 2003, 125, 10899; (d) D. A. Evans, P. Nagorny, D. J. Reynolds and K. J. McRae, Angew. Chem., Int. Ed., 2007, 46, 541; (e) C. J. Hayes and C. H. Heathcock, J. Org. Chem., 1997, 62, 2678; (f) C. Schneider and M. Rehfeuter, Tetrahedron Lett., 1998, 39, 9; (g) C. Schneider and M. Rehfeuter, Chem.-Eur. J., 1999, 5, 2850; (h) H. Hayakawa and M. Miyashita, Tetrahedron Lett., 2000, 41, 707; (i) J. Tholander and E. M. Carreira, Helv. Chim. Acta, 2001, 84, 613; (j) Y. Wang, Y. Xing, Q. Zhang and G. A. O'Doherty, Chem Commun., 2011, 47, 8493; (k) Y. Wang and G. A. O'Doherty, J. Am. Chem. Soc., 2013, 135, 9334; (I) S. E. Denmark and S. Fujimori, J. Am. Chem. Soc., 2005, 127, 8971; (m) A. Vincent and J. Prunet, Synlett, 2006, 2269; (n) E. de Lemos, F.-H. Porée, A. Commerçon, J.-F. Betzer, A. Pancrazi and J. Ardisson, Angew. Chem., Int. Ed., 2007, 46, 1917; (o) E. de 
Lemos, F.-H. Porée, A. Bourin, J. Barbion, E. Agouridas, M.-I. Lannou, A. Commerçon, J.-F. Betzer, A. Pancrazi and J. Ardisson, Chem.-Eur. J., 2008, 14, 11092; (p) A. Dittoo, V. Bellosta and J. Cossy, Synlett, 2008, 2459; (q) S. Chandrasekhar, C. Rambabu and A. S. Reddy, Tetrahedron Lett., 2008, 49, 4476; (r) T. Ehara, M. Fujii, M. Ono and H. Akita, Tetrahedron: Asymmetry, 2010, 21, 494; (s) J. S. Yadav and G. Rajendar, Eur. J. Org. Chem., 2011, 6781; (t) J. S. Yadav, D. C. Bhunia, B. Ganganna and V. K. Singh, RSC Adv. 2013, 3, 5254; (u) P. Sawant and M. E. Maier, Eur. J. Org. Chem., 2012, 6576; (v) A. M. M. Albury and M. P. Jennings, J. Org. Chem., 2012, 77, 6929; (w) Y. Kawato, S. Chaudhary, N. Kumagai and M. Shibasaki, Chem.-Eur. J., 2013, 19, 3802; (x) Y. Luo, I. D. Roy, A. G. E. Madec and H. W. Lam, Angew. Chem., Int. Ed., 2014, 53, 4186; (y) Y. Wang and W.-M. Dai, Eur. J. Org. Chem., 2014, 323; (z) P. A. Evans, M.-H. Huang, M. J. Lawler and S. Maroto, Nat. Chem., 2012, 4, 680.

5 (a) D. A. Evans and J. A. Gauchet-Prunet, J. Org. Chem., 1993, 58, 2446; (b) P. A. Evans, A. Grisin and M. J. Lawler, J. Am. Chem. Soc., 2012, 134, 2856; (c) H. Watanabe, K. Machida, D. Itoh, H. Nagatsuka and T. Kitahara, Chirality, 2001, 13, 379.

6 (a) K. Asano and S. Matsubara, J. Am. Chem. Soc., 2011, 133, 16711; (b) K. Asano and S. Matsubara, Org. Lett., 2012, 14, 1620; (c) T. Okamura, K. Asano and S. Matsubara, Chem. Commun., 2012, 48, 5076; (d) Y. Fukata, R. Miyaji, T. Okamura, K. Asano and S. Matsubara, Synthesis, 2013, 45, 1627; (e) R. Miyaji, K. Asano and S. Matsubara, Org. Biomol. Chem., 2014, 12, 119; (f) N. Yoneda, A. Hotta, K. Asano and S. Matsubara, Org. Lett., 2014, 16, 6264.

7 For our related works on intramolecular aza-Michael addition by bifunctional organocatalysts, see: (a) R. Miyaji, K. Asano and S. Matsubara, Org. Lett., 2013, 15, 3658; (b) Y. Fukata, K. Asano and S. Matsubara, J. Am. Chem. Soc., 2013, 135, 12160; (c) Y. Fukata, K. Asano and S. Matsubara, Chem. Lett., 2013, 42, 355.

8 For an intramolecular oxy-Michael addition of boronic acid hemiesters by bifunctional organocatalysts; see: D. R. Li, A. Murugan and J. R. Falck, J. Am. Chem. Soc., 2008, 130, 46.

9 (a) T. Akiyama, J. Itoh, K. Yokota and K. Fuchibe, Angew. Chem., Int. Ed., 2004, 43, 1566; (b) D. Uraguchi and M. Terada, J. Am. Chem. Soc., 2004, 126, 5356; for reviews, see: (c) M. Terada, Synthesis, 2010, 1929; (d) T. Akiyama, Chem. Rev., 2007, 107, 5744.

10 For an example of desymmetrization via a hemiacetalization/intramolecular oxy-Michael addition cascade by a chiral phosphoric acid catalyst, see: D. M. Rubush, M. A. Morges, B. J. Rose, D. H. Thamm and T. Rovis, J. Am. Chem. Soc., 2012, 134, 13554.

11 For selected examples of asymmetric formation of acetals by chiral Brønsted acid catalysts, see: (a) I. Čorić, S. Vellalath and B. List, J. Am. Chem. Soc., 2010, 132, 8536; (b) I. Čorić, S. Müller and B. List, J. Am. Chem. Soc., 2010, 132, 17370; (c) I. Čorić and B. List, Nature, 2012, 483, 315; (d) Z. Sun, G. A. Winschel, A. Borovika and P. Nagorny, J. Am. Chem. Soc., 2012, 134, 8074; (e) J. H. Kim, I. Čorić, S. Vellalath and B. List, Angew. Chem., Int. Ed., 2013, 52, 4474; (f) L. Qiu, X. Guo, C. Ma, H. Qiu, S. Liu, L. Yang and W. Hu, Chem. Commun., 2014, 50, 2196; (f) T. Yamanaka, A. Kondoh and M. Terada, J. Am. Chem. Soc., 2015, 137, 1048; (g) J. H. Kim, I. Čorić, C. Palumbo and B. List, J. Am. Chem. Soc., 2015, 137, 1778.

12 Similar observations were reported in ref $5 \mathrm{~b}$. For quantification of the electrophilic reactivity of aldehydes, see: R. Appel and H. Mayr, J. Am. Chem. Soc., 2011, 133, 8240.

13 Further details on screening of reaction conditions are described in the SI (Tables S1).

14 Reduction of 3ef with the same protocol was also carried out $(d r=11: 1)$, and the relative configuration of the major product was assigned as syn by X-ray analysis (see the SI for details). 